\title{
Salvage living donor liver transplantation for
} posthepatectomy recurrence: a higher incidence of recurrence but promising strategy for long-term survival

This article was published in the following Dove Press journal:

Cancer Management and Research

\section{Kun-Ming Chan \\ Chih-Hsien Cheng \\ Tsung-Han Wu \\ Chen-Fang Lee \\ Ting-Jung Wu \\ Hong-Shiue Chou \\ Wei-Chen Lee}

Department of General Surgery, Chang Gung Memorial Hospital at Linkou, Chang Gung University College of Medicine, Taoyuan, Taiwan
Correspondence: Kun-Ming Chan Department of General Surgery, Chang Gung Memorial Hospital at Linkou, Chang Gung University College of Medicine, 5 Fu-Hsing Street, Gui-Shan District, Taoyuan City 33305, Taoyuan, Taiwan Tel +8863328 I200 Ext 3366

Email chankunming@adm.cgmh.org.tw
Background: The scarcity of deceased donor organ donation has led to increasing utilization of living donor liver transplantation (LDLT), which is an optimal treatment for cirrhosis associated with hepatocellular carcinoma (HCC). The study thus aims to analyze prognostic factors and beneficial effects of LDLT for patients with HCC.

Methods: All patients who underwent LDLT for HCC were included in this study. A multivariate analysis of patients' clinicopathologic parameters was performed to determine prognostic factors. Subsequently, the type of LDLT was further analyzed and compared based on the result of multivariate analysis.

Results: Overall, 36 (11.9\%) of 303 patients were identified as having HCC recurrence after LDLT. Salvage LDLT (sLDLT) defined by liver transplantation for those patients with recurrent $\mathrm{HCC}$ after primary liver resection (LR) was identified as the major prognostic factor of HCC recurrence following the transplantation $(\mathrm{HR}=2.49[1.12-5.54], p=0.025)$. The HCC recurrence incidence and recurrence-free survival after LDLT were significantly inferior in the salvage group than the other group. The pre-transplantation factors were further evaluated and resulted in only maximum tumour size $\geq 5 \mathrm{~cm}$ at primary $\mathrm{LR}(\mathrm{HR}=10.79[2.10$ 55.43], $p=0.004$ ) affecting post-transplantation HCC recurrence in those patients who had been performed sLDLT. However, patients receiving salvage LDLT had 5- and 10-year overall survival of $86.7 \%$ and $52.9 \%$, respectively, measured from the time of initial HCC diagnosis.

Conclusion: Overall, LDLT achieves a satisfactory result with low incidence of HCC recurrence based on certain transplantation criteria. Despite the higher incidence of HCC recurrence after sLDLT, it remains a promising strategy to improve long-term outcomes.

Keywords: hepatocellular carcinoma, living donor liver transplantation, salvage, recurrence, prognosis

\section{Introduction}

Liver transplantation (LT) had been considered the optimal treatment option for patients with cirrhosis accompanied by hepatocellular carcinoma (HCC) under certain circumstances. ${ }^{1}$ Theoretically, LT can completely remove tumors and also cure underlying cirrhotic liver that renders a pathogenic environment for HCC development. Moreover, LT has now become a common and routine operation because of growing experience, and the success of LT for HCC has been widely 
reported in many transplantation centers worldwide. ${ }^{2,3}$ However, additional information related to living donor liver transplantation (LDLT) remains an issue of great importance in order to optimize therapeutic strategies for patients with HCC.

This study retrospectively analyzed patients who underwent LDLT accompanied with HCC. Apart from that, prognostic factors associated with patient outcomes and beneficial effects of LDLT in patients with HCC were also examined. Meanwhile, the type of LDLT in terms of primary or salvage LDLT (sLDLT) was further analyzed and compared based on the result of prognostic factor analysis. As such, the concept of salvage LT has become an ideal strategy to extend survival time for patients with recurrent HCC after primary liver resection (LR). ${ }^{4-6}$ Therefore, the study also reviewed patients who had undergone sLDLT, and examined pre-transplantation risk factors associated with the outcome of patients as well as providing additional information for optimizing therapeutic strategy in patients with HCC.

\section{Materials and methods}

\section{Patients}

All medical records of patients who underwent LDLT at the Organ Transplantation Institute of Chang Gung Memorial Hospital at Linkou, Taiwan, were retrospectively reviewed under the approval from the Institutional Review Board (approval no. 98-3794B), and informed consent from patient was waived because of the retrospective nature of the study. The study protocol also complied with the ethical standards established by the Declaration of Helsinki in terms of patient data confidentiality. A total of 701 consecutive LDLTs were performed between July 2001 and February 2018 at the transplantation center. Subsequently, patients who underwent LDLT for cirrhosis associated with HCC were enrolled. As a result, 303 patients consisting of 244 males and 59 females were eligible for this study, and clinical information, including recipients' demographic, medical, transplantation, and follow-up data was collected for analysis.

\section{Definition and LT}

The HCC treatment was decided mainly based on the consensus of multidisciplinary liver cancer committee, including the surgeons, hepatologists, pathologists, medical oncologists, and radiologists in the institute. Generally, LR was the preferred option in resectable HCC. LT was recommended for patients with end-stage liver disease and/or unresectable $\mathrm{HCC}$ that met the proposed criteria from the University of California at San Francisco (UCSF) according to imaging results of tumor characteristics in terms of size and number. ${ }^{3}$ Patients with HCC beyond the aforementioned criteria were subjected to locoregional therapy for down-staging prior to LT. Subsequently, patients who were successfully down-staged to meet the transplantation criteria and stable for at least 3 months would be subjected to LT, and LDLT could be performed shortly if living donor available.

LDLTs were performed using standard techniques without venovenous bypass as previously described. ${ }^{7}$ sLDLT was defined as LT performed in patients who previously underwent LR for HCC, followed by LT for end-stage liver cirrhosis associated with recurrent HCC. None of the patients underwent sLDLT because of acute decompensation of liver function immediately after LR in this study. Primary LDLT (pLDLT) was defined as LT for patients with cirrhosis accompanied by unresectable HCC, who has not undergone LR for HCC prior to LT. Additionally, all enrolled patients were definitively diagnosed with HCC pathologically from either LR resected liver specimen or LT explanted liver specimen. After LT, the protocol of immunosuppressant regimen and recipient follow-up was followed as previously described. ${ }^{8,9}$ Briefly, patients were regularly followed up for alpha-fetoprotein measurements, liver ultrasonography, and radiologic imaging examination including computed tomography and/or magnetic resonance imaging after LT. Generally, radiologic imaging was routinely performed at 1, 3, 6, 12 months and every year afterward or a suspicious of HCC recurrence. Liver ultrasonography was generally performed every 3 months if radiologic imaging was not arranged. However, tumor biopsy was performed only in the case of equivocal imaging readings or whenever clinically indicated.

\section{Statistical analysis}

Categorical clinicopathologic variables were compared using the $\chi^{2}$ or Fisher exact test as appropriate. Continuous variables were expressed as median and range and compared using the Student's $t$ test. The survival curves were constructed using the Kaplan-Meier method and compared using the log-rank test. Variables were analyzed using the Cox proportional hazards regression model to identify factors influencing the outcomes after LT. Recurrence-free survival (RFS) was defined as from 
the date of LT to HCC recurrence, and overall survival (OS) was calculated from the date of HCC diagnosis or LT to death or until the end of this study. All significant prognostic factors determined by univariate analysis were further selected for multivariate analysis in a forward stepwise manner. All data analyses were performed using the SPSS statistical software package version 25.0 (SPSS, Inc., Chicago, IL, USA) for Windows. A statistical $p$-value of $<0.05$ was considered significantly different.

\section{Results}

\section{HCC recurrence after LDLT}

Overall, $17(5.6 \%)$ patients died at the hospital from 4 days to 2.6 months among the 303 patients after LDLT. Thirty-six patients were identified with HCC recurrence during a follow-up period from 3.2 to 172.2 months for the remaining patients, accounting for $11.9 \%$ of all 303 patients and $12.6 \%$ of patients after excluding hospital mortalities in this study. The median duration of initial HCC recurrence after LDLT was 14.7 (range, 1.2-92.5) months. The initial HCC recurrence was detected in 8 patients with intrahepatic metastasis only, 9 with extrahepatic metastasis, and 19 with systemic spread, including intrahepatic and extrahepatic locations. Among them, five patients underwent surgical resection for isolated extrahepatic metastasis, and two of them is still alive without $\mathrm{HCC}$ at the end of this study. Eventually, 28 patients died of HCC recurrence during the follow-up period.

\section{Prognostic factors of HCC recurrence after LDLT}

The prognostic factors for HCC recurrence after LDLT were analyzed according to the clinical features, including perioperative parameters and patients' pathologic tumor characteristics, and are summarised in Table 1. The univariate analysis identified nine significant factors, such as the recipient's age at transplantation, Child-Pugh class of cirrhosis, LT type, number of tumors, total tumor size, histologic grade of HCC, microvascular invasion, Milan transplantation criteria, and UCSF transplantation criteria. Furthermore, the multivariate regression analysis results of the aforementioned factors were sLDLT $(\mathrm{HR}=2.49,95 \% \mathrm{CI}=1.12-5.54, p=0.025)$ and Milan criteria $(\mathrm{HR}=7.1,95 \% \mathrm{CI}=1.86-27.25, p=0.004)$ as the independent risk factors affecting the HCC recurrence after LDLT. (Table 2)

\section{sLDLT versus pLDLT}

Based on the analysis results of the prognostic factor, the clinicopathologic features of recipients in terms of transplantation type were compared between the sLDLT and pLDLT groups (Table 3). Numerous clinical features were significantly different between the two groups. Briefly, recipients within the sLDLT groups had significantly lower age, lower HCV ratio, higher percentage of Child class A as early cirrhosis, less ascites and intraoperative blood loss, elderly donor age, and smaller maximum tumor size. Surprisingly, the duration of complete liver mobilization and total operative time were not different between the two groups despite of sLDLT with the previous LR for primary HCC. Additionally, the intraoperative blood loss was also not affected by repeat operation in the sLDLT group.

Additionally, outcomes after the LT were analyzed and compared between the sLDLT and pLDLT groups. The comparison of RFS curves in patients after LT is illustrated in Figure 1A, and recipients in the sLDLT group had significantly lower survival curves as compared with the pLDLT group $(p=0.002)$. The RFS for 1,3 , and 5 years was $86.6 \%, 72.9 \%$, and $72.9 \%$, respectively, in the sLDLT group, whereas the RFS for 1, 3, and 5 years was $95.7 \%$, $91.1 \%$, and $88.5 \%$, respectively, in the pLDLT group. However, no significant difference in OS curves was found between the two groups (Figure $1 \mathrm{~B}, p=0.326$ ). The cumulative OS for 1,3 , and 5 years in the sLDLT was $85.8 \%, 67.0 \%$, and $61.6 \%$, respectively, and those in the pLDLT were $84.3 \%, 78.3 \%$, and $71.8 \%$, respectively.

\section{Pre-transplantation factors affecting outcomes after sLDLT}

The pre-transplantation risk factors for $\mathrm{HCC}$ recurrence after sLDLT were evaluated as well. The clinical features of patients associated with primary LR and LT were analyzed for prognostic factors affecting $\mathrm{HCC}$ recurrence after sLDLT using univariate and multivariate analysis (Table 4). Of those, univariate analysis identified two significant factors including LR $\geq 3$ segments, maximum tumor size $\geq 5 \mathrm{~cm}$ were associated with primary LR, and four significant factors including tumor number $>3$ nodules, maximum tumor size $>3 \mathrm{~cm}$, beyond Milan criteria and beyond UCSF criteria were related to posthepatectomy recurrent HCC. Furthermore, multivariate regression analysis of these factors showed maximum tumor size $\geq 5 \mathrm{~cm}$ at primary LR (HR=10.79, 95\% 
Table I Univariate analysis of factors affecting recurrence-free survival

\begin{tabular}{|c|c|c|c|c|}
\hline & $\mathbf{n}$ & Mean RFS (months) & HR, 95\% Cl & $P$-value \\
\hline \multicolumn{5}{|l|}{ Age } \\
\hline$<55$ & 129 & 135.7 & $2.16(1.10-4.23)$ & 0.024 \\
\hline$\geq 55$ & 174 & 152.4 & 1 & \\
\hline \multicolumn{5}{|l|}{ Gender } \\
\hline Female & 59 & 125.0 & 1 & 0.679 \\
\hline Male & 244 & 145.4 & $1.20(0.50-2.89)$ & \\
\hline \multicolumn{5}{|l|}{$\operatorname{AFP}(\mathrm{ng} / \mathrm{mL})$} \\
\hline$<400$ & 276 & 147.9 & I & 0.073 \\
\hline$\geq 400$ & 27 & 100.5 & $2.23(0.93-5.36)$ & \\
\hline \multicolumn{5}{|l|}{ Hepatitis B virus } \\
\hline Yes & 208 & 143.8 & $1.40(0.66-2.98)$ & 0.378 \\
\hline No & 95 & 127.3 & 1 & \\
\hline \multicolumn{5}{|l|}{ Hepatitis C virus } \\
\hline Yes & 91 & 151.3 & 1 & 0.247 \\
\hline No & 212 & 143.5 & $1.59(0.73-3.49)$ & \\
\hline \multicolumn{5}{|l|}{ Child class } \\
\hline A & 139 & 136.5 & $2.28(1.14-4.55)$ & 0.020 \\
\hline B, C & 164 & 154.3 & 1 & \\
\hline \multicolumn{5}{|l|}{ MELD score } \\
\hline$<20$ & 272 & 143.9 & I.73 (0.4I-7.20) & 0.450 \\
\hline$\geq 20$ & 31 & 155.4 & 1 & \\
\hline \multicolumn{5}{|c|}{ Year of transplantation } \\
\hline $200 I-2010$ & 117 & 147.0 & 1 & 0.878 \\
\hline $2011-2018$ & 186 & 82.8 & $1.05(0.53-2.07)$ & \\
\hline \multicolumn{5}{|c|}{ Transplantation type } \\
\hline Salvage & 58 & 106.7 & $2.78(0.4 I-5.50)$ & 0.003 \\
\hline Primary & 245 & 150.8 & 1 & \\
\hline \multicolumn{5}{|c|}{ Previous treatment for $\mathrm{HCC}$} \\
\hline Yes & 253 & 143.4 & $1.55(0.55-4.39)$ & 0.407 \\
\hline No & 50 & 154.2 & 1 & \\
\hline \multicolumn{5}{|l|}{ Ascites $(\mathrm{mL})$} \\
\hline$<1000$ & 236 & 145.3 & 1 & 0.733 \\
\hline$\geq 1000$ & 67 & 144.0 & $1.14(0.52-2.52)$ & \\
\hline \multicolumn{5}{|l|}{ Blood loss (mL) } \\
\hline$<2000$ & 197 & 144.3 & 1 & 0.860 \\
\hline$\geq 2000$ & 106 & 147.1 & $0.94(0.46-1.91)$ & \\
\hline \multicolumn{5}{|l|}{ GRWR } \\
\hline$<0.8 \%$ & 69 & 135.8 & 1 & 0.758 \\
\hline$\geq 0.8 \%$ & 234 & 145.7 & $1.14(0.50-2.60)$ & \\
\hline \multicolumn{5}{|l|}{ Graft type } \\
\hline Right liver graft & 284 & 147.5 & 1 & 0.123 \\
\hline Left liver graft & 19 & 81.8 & $2.27(0.80-6.42)$ & \\
\hline
\end{tabular}

(Continued) 
Table I (Continued).

\begin{tabular}{|c|c|c|c|c|}
\hline & $\mathbf{n}$ & Mean RFS (months) & $\mathrm{HR}, 95 \% \mathrm{Cl}$ & $P$-value \\
\hline \multicolumn{5}{|l|}{ Donor gender } \\
\hline Male & 170 & 146.0 & $1.01(0.52-1.95)$ & 0.985 \\
\hline Female & 133 & 131.9 & 1 & \\
\hline \multicolumn{5}{|l|}{ Donor age } \\
\hline$<40$ & 253 & 148.7 & 1 & 0.070 \\
\hline$\geq 40$ & 50 & 130.6 & $2.01(0.95-4.28)$ & \\
\hline \multicolumn{5}{|l|}{ Tumor number } \\
\hline$\leq 3$ & 233 & 153.2 & 1 & 0.001 \\
\hline$>3$ & 70 & 113.9 & $3.03(1.57-5.83)$ & \\
\hline \multicolumn{5}{|l|}{ Maximum tumor size $(\mathrm{cm})$} \\
\hline$\leq 5$ & 276 & 147.4 & 1 & 0.338 \\
\hline$>5$ & 27 & II5.I & $1.67(0.59-4.72)$ & \\
\hline \multicolumn{5}{|l|}{ Sum of tumor size $(\mathrm{cm})$} \\
\hline$\leq 8$ & 248 & 153.6 & 1 & $<0.0001$ \\
\hline$>8$ & 55 & 109.3 & $4.10(2.12-7.95)$ & \\
\hline \multicolumn{5}{|l|}{ Histology grade } \\
\hline Grade I, 2 & 229 & 151.5 & 1 & 0.005 \\
\hline Grade 3, 4 & 74 & 127.7 & $2.60(1.33-5.04)$ & \\
\hline \multicolumn{5}{|l|}{ Microvascular invasion } \\
\hline Yes & 53 & 105.1 & I & $<0.001$ \\
\hline No & 250 & 152.9 & $3.60(1.85-6.99)$ & \\
\hline \multicolumn{5}{|l|}{ Milan } \\
\hline Within & 201 & 158.2 & I & $<0.00001$ \\
\hline Beyond & 102 & 116.7 & 4.91 (2.45-9.84) & \\
\hline \multicolumn{5}{|l|}{ UCSF } \\
\hline Within & 217 & 156.3 & I & $<0.0001$ \\
\hline Beyond & 86 & 115.6 & $4.23(2.18-8.23)$ & \\
\hline
\end{tabular}

Abbreviations: AFP, alpha-fetoprotein; MELD, model for end-stage liver disease; HCC, hepatocellular carcinoma; GRWR; graft recipient weight ratio; UCSF, university of california san francisco; RFS, recurrence-free survival.

Table 2 Multivariate analysis of all significant factors affecting recurrence-free survival

\begin{tabular}{|l|l|l|}
\hline & $p$ & Hazard ratio $\mathbf{9 5 \%} \mathbf{C l})$ \\
\hline Age <55 years & 0.073 & $1.89(0.94-3.82)$ \\
Child-Pugh class A & 0.249 & $1.59(0.72-3.52)$ \\
Salvage LDLT & 0.025 & $2.49(1.12-5.54)$ \\
Tumor number >3 & 0.630 & $0.76(0.26-2.24)$ \\
Sum of tumor size >8 cm & 0.437 & $1.44(0.57-3.67)$ \\
Histology grade 3, 4 & 0.102 & $1.82(0.88-3.77)$ \\
Microvascular invasion & 0.103 & $1.92(0.87-4.22)$ \\
Beyond Milan criteria & 0.004 & $7.12(1.86-27.25)$ \\
Beyond UCSF criteria & 0.652 & $0.69(0.14-3.39)$ \\
\hline
\end{tabular}

Abbreviations: LDLT, living donor liver transplantation; UCSF, university of california san francisco.
$\mathrm{CI}=2.10-55.43, p=0.004)$ as the only independent risk factor affecting HCC recurrence after sLDLT.

Subsequently, outcome analysis showed that patients in the sLDLT group had remarkably extended survival time for patients, the 1-, 3-, 5-, and 10-year OS rates measured from the time of HCC diagnosis were $100 \%, 96.6 \%$, $86.7 \%$, and $52.9 \%$, respectively (Figure 2).

\section{Discussion}

The great success in LT has changed the therapeutic landscape for the treatment of patients with concurrent liver cirrhosis and HCC ineligible for curative LR. ${ }^{2,3}$ However, the endemic variance regarding the prevalence of organ 
Table 3 Comparison of clinicopathological and demographic features of patients based on transplantation type

\begin{tabular}{|c|c|c|c|}
\hline & Salvage LDLT & Primary LDLT & $P$-value \\
\hline & $n=58(\%)$ & $n=245$ (\%) & \\
\hline \multicolumn{4}{|l|}{ Age (years) } \\
\hline Median (range) & $54(13-69)$ & $57(33-70)$ & 0.027 \\
\hline \multicolumn{4}{|l|}{ Gender } \\
\hline Female:Male & $8: 50$ & $51: 194$ & 0.225 \\
\hline \multicolumn{4}{|l|}{$\operatorname{AFP}(n g / m L)$} \\
\hline Median (range) & $9(|.3-2| 8 \mid)$ & $12(1.7-18,250)$ & 0.416 \\
\hline \multicolumn{4}{|l|}{ Hepatitis $B$ virus } \\
\hline Yes & $45(77.6)$ & $163(66.5)$ & 0.103 \\
\hline No & $13(22.4)$ & $82(33.5)$ & \\
\hline \multicolumn{4}{|l|}{ Hepatitis C virus } \\
\hline Yes & $6(10.3)$ & $85(34.7)$ & $<0.001$ \\
\hline No & $52(89.7)$ & $160(65.3)$ & \\
\hline \multicolumn{4}{|l|}{ Child class } \\
\hline A & $42(72.4)$ & 97 (39.6) & $<0.0001$ \\
\hline B, C & $16(27.6)$ & $148(60.4)$ & \\
\hline \multicolumn{4}{|l|}{ MELD score } \\
\hline Median (range) & $8.0(5.0-18.0)$ & $12.0(6.0-36.0)$ & $<0.0001$ \\
\hline \multicolumn{4}{|c|}{ Pre-transplantation locoregional therapy } \\
\hline Yes & $51(87.9)$ & $202(82.4)$ & 0.312 \\
\hline No & $7(12.1)$ & $43(17.6)$ & \\
\hline \multicolumn{4}{|l|}{ Ascites (mL) } \\
\hline Median (range) & $0(0-11,000)$ & $0(0-14,400)$ & $<0.001$ \\
\hline \multicolumn{4}{|l|}{ Blood loss (mL) } \\
\hline Median (range) & $875(100-13,000)$ & $1400(50-23,400)$ & 0.012 \\
\hline \multicolumn{4}{|c|}{ Liver mobilization (min) } \\
\hline Median (range) & $309(182-518)$ & $310(165-532)$ & 0.868 \\
\hline \multicolumn{4}{|c|}{ Total operative time $(\min )$} \\
\hline Median (range) & $680(390-1025)$ & $659(352-1046)$ & 0.239 \\
\hline \multicolumn{4}{|l|}{ GRWR } \\
\hline Median (range) & $0.87(0.5 \mathrm{I}-\mathrm{I} .44)$ & $0.92(0.58-1.79)$ & 0.069 \\
\hline \multicolumn{4}{|l|}{ Graft type } \\
\hline Right liver graft & $52(89.7)$ & $232(94.7)$ & 0.222 \\
\hline Left liver graft & $6(10.3)$ & $13(5.3)$ & \\
\hline \multicolumn{4}{|l|}{ Donor gender } \\
\hline Female:male & $28: 30$ & $105: 140$ & 0.455 \\
\hline \multicolumn{4}{|l|}{ Donor age (years) } \\
\hline Median (range) & $33(18-58)$ & $30(18-55)$ & 0.013 \\
\hline \multicolumn{4}{|l|}{ Tumor number } \\
\hline Median (range) & $2(I-20)$ & $2(I-22)$ & 0.707 \\
\hline
\end{tabular}


Table 3 (Continued).

\begin{tabular}{|c|c|c|c|}
\hline & Salvage LDLT & Primary LDLT & $P$-value \\
\hline & $n=58(\%)$ & $n=245(\%)$ & \\
\hline \multicolumn{4}{|c|}{ Maximum tumor size $(\mathrm{cm})$} \\
\hline Median (range) & $2.0(0.5-6.0)$ & $2.5(0.6-11.2)$ & 0.018 \\
\hline \multicolumn{4}{|c|}{ Sum of tumor size $(\mathrm{cm})$} \\
\hline Median (range) & $3.1(0.5-20.1)$ & $4.0(0.6-20.1)$ & 0.222 \\
\hline \multicolumn{4}{|l|}{ Histology grade } \\
\hline Grade I, 2 & $43(74.1)$ & $186(75.9)$ & 0.777 \\
\hline Grade 3, 4 & $15(25.9)$ & $59(24.1)$ & \\
\hline \multicolumn{4}{|c|}{ Microvascular invasion } \\
\hline Yes & $13(22.4)$ & $40(16.3)$ & 0.273 \\
\hline No & $45(77.6)$ & $205(83.7)$ & \\
\hline \multicolumn{4}{|l|}{ Milan } \\
\hline Within & $43(74.1)$ & $158(64.5)$ & 0.162 \\
\hline Beyond & $15(25.9)$ & $87(35.5)$ & \\
\hline \multicolumn{4}{|l|}{ UCSF } \\
\hline Within & 44 (75.9) & $173(70.6)$ & 0.425 \\
\hline Beyond & $14(24.1)$ & $72(29.4)$ & \\
\hline Hospital mortality & $3(5.2)$ & $14(5.7)$ & 0.361 \\
\hline
\end{tabular}

Abbreviations: LDLT, living donor liver transplantation; AFP, alpha-fetoprotein; MELD, model for end-stage liver disease; HCC, hepatocellular carcinoma; GRWR, graft recipient weight ratio; UCSF, university of california san francisco.

A

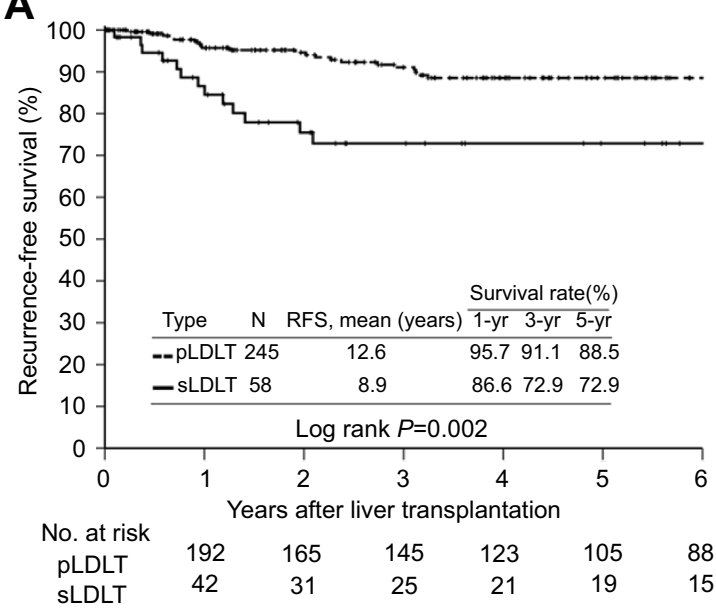

B

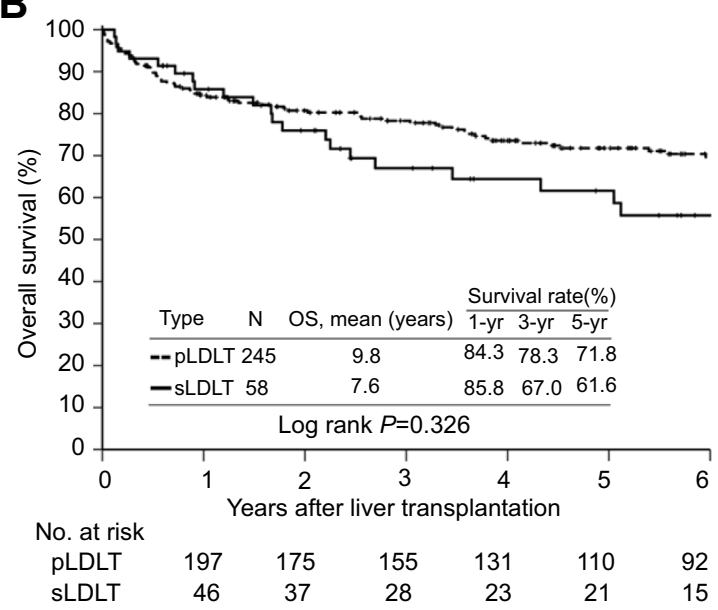

Figure I Kaplan-Meier survival curves in patients according to the type of living donor liver transplantation. (A) Recurrence-free survival ( $p=0.002)$. (B) Overall survival $(p=0.326)$.

donation from deceased donors divides LT into two major categories developed in different regions, ie, DDLT was popular in the Western countries and LDLT was predominant in most East Asian countries. ${ }^{10-12}$ As one of the most common malignancies leading to cancer-related deaths worldwide, efforts have been continued to improve treatment strategies in patients with HCC in terms of better outcomes. Despite the similar entity existing in the LT concept in a patient with HCC, LDLT is dissimilar from DDLT in numerous circumstances. ${ }^{13-15}$ Importantly, HCC recurrence remains the major concern in not only DDLT but also LDLT. In this study, LDLT based on the UCSF 
Table 4 Univariate and multivariate analyses of pretransplantation factors affecting HCC recurrence of patients after salvage living donor liver transplantation $(n=58)$

\begin{tabular}{|c|c|c|c|c|c|}
\hline \multirow[t]{2}{*}{ Factors (patient number) } & \multicolumn{3}{|c|}{ Univariate analysis } & \multicolumn{2}{|c|}{ Multivariate analysis } \\
\hline & HR & $95 \% \mathrm{Cl}$ & $p$-value & HR (95\% Cl) & $p$-value \\
\hline Sex (male, female) (50 vs 8 ) & 0.64 & $0.14-2.93$ & 0.572 & - & - \\
\hline Hepatitis B virus (positive, negative) (52 vs 6 ) & 0.49 & $0.11-2.25$ & 0.365 & - & - \\
\hline Hepatitis C virus (positive, negative) (6 vs 52 ) & 0.04 & $0.00-154.38$ & 0.451 & - & - \\
\hline \multicolumn{6}{|l|}{ Liver resection } \\
\hline Age at LR $(<55, \geq 55$ years) ( 4 I vs I 7$)$ & 2.16 & $0.47-9.75$ & 0.316 & - & - \\
\hline Extent of $\operatorname{LR}(>3,<3$ segments) (12 vs 46$)$ & 3.55 & $1.13-11.12$ & 0.029 & - & NS \\
\hline Tumor number (single, multiple) (5I vs 7 ) & 0.43 & $0.11-1.56$ & 0.201 & - & - \\
\hline Maximum tumor size $(\geq 5,<5 \mathrm{~cm})(17$ vs $4 \mathrm{I})$ & 6.18 & $1.99-19.18$ & 0.002 & $10.79(2.10-55.43)$ & 0.004 \\
\hline Microvascular invasion (yes, no) (7 vs 5I) & 1.82 & $0.40-8.29$ & 0.435 & - & - \\
\hline Satellite nodule (yes, no) (12 vs 46$)$ & 1.72 & $0.53-5.60$ & 0.365 & - & - \\
\hline Histology grade (I/II, III/IV) (46 vs I2) & 0.74 & $0.16-3.34$ & 0.697 & - & - \\
\hline Recurrent time after LR ( $\geq 1,<1$ year) (40 vs I8) & 1.90 & $0.64-5.68$ & 0.246 & - & - \\
\hline Times of liver resection $(I,>1)(52$ vs 6$)$ & 1.86 & $0.4 \mid-8.48$ & 0.419 & - & - \\
\hline \multicolumn{6}{|l|}{ Liver transplantation } \\
\hline Age at LT (<55, $\geq 55$ years) ( 32 vs 26$)$ & 2.91 & $0.80-10.58$ & 0.105 & - & - \\
\hline $\operatorname{AFP}(\geq 400,<400 \mathrm{ng} / \mathrm{mL})(7 \mathrm{vs} 5 \mathrm{I})$ & 2.21 & $0.60-8.04$ & 0.229 & - & - \\
\hline MELD score $(\geq 20,<20)$ (0 vs 58$)$ & - & - & - & - & - \\
\hline Child class $(A, B / C)(43$ vs 15$)$ & 0.30 & $0.04-2.38$ & 0.260 & - & - \\
\hline Tumor number $(>3, \leq 3)$ (II vs 47$)$ & 4.48 & $1.49-13.43$ & 0.007 & - & NS \\
\hline Maximum tumor size $(>3, \leq 3 \mathrm{~cm})($ I I vs 47$)$ & 3.74 & $1.20-11.60$ & 0.022 & - & NS \\
\hline Milan criteria (beyond, within) (18 vs 40 ) & 5.94 & $1.82-19.43$ & 0.003 & - & NS \\
\hline UCSF (beyond, within) (13 vs 45$)$ & 7.25 & $2.34-22.46$ & 0.001 & - & NS \\
\hline
\end{tabular}

Abbreviations: HCC, hepatocellular carcinoma; LR, liver resection; LT, liver transplantation; AFP, alpha-fetoprotein; MELD, model for end-stage liver disease; UCSF, university of california at san francisco; NS, no significance.

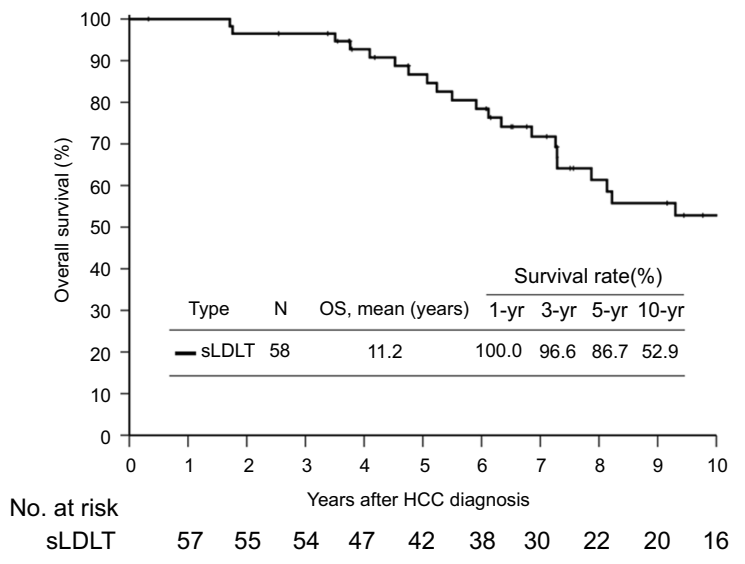

Figure 2 The cumulative overall survival was calculated from the time of initial hepatocellular carcinoma diagnosis in patients who underwent salvage living donor liver transplantation.

criteria has a satisfactory low ratio of HCC recurrence. Moreover, a higher incidence of HCC recurrence after LDLT seems to occur in certain patient populations such as those who underwent previous hepatectomy for primary HCC, known as SLDLT.

Currently, LT has become a common and routine operation in many major transplantation centers worldwide. However, the high endemicity of hepatitis and its long-term sequelae has increased the high incidence of liver diseases as well as liver cancer in Asia. With the very low deceased donor organ donation rates, the need for solutions had turned into flourish of LDLT in this region. Theoretically, LDLT would not jeopardize the chance of LT in other patients on the waiting list. Therefore, most Asian countries had established their selecting criteria in HCC for LT and showed comparable outcomes as the initial report based on Milan criteria. ${ }^{16-19}$ Under the Taiwan National Health Insurance (NHI) program, LDLT was approved for patients with HCC that only met the expanded criteria of the UCSF according to imaging characteristics of tumor size and number. By following the NHI program regulations, a satisfactory result on low 
incidence of HCC recurrence after LDLT was achieved in this study. However, unlimited expansion of the selection criteria should be cautiously considered as HCC recurrence may too high to reflect the benefit of LDLT for $\mathrm{HCC}^{20,21}$

Although several LT prognostic factors for HCC had been reported from our institute as well as others, predictors of HCC recurrence after LDLT might be a different scenario. Based on our data, sLDLT was found to be the major independent factor for prognosis, implying that recurrent $\mathrm{HCC}$ from previous LR was a significant factor affecting the outcome following LDLT. Additionally, large tumor size at primary LR, for example, more than $5 \mathrm{~cm}$ as shown in the study could possibly affect HCC recurrence after sLDLT, indicating HCC features at primary LR should also be taken into consideration and cautious about HCC recurrence even after salvage LT.

Moreover, adverse tumor behaviors that may result in HCC recurrence after transplantation cannot be identified using the pre-transplantation survey despite meeting the UCSF criteria. Therefore, HCC recurrence from previous LR might lead one to infer that its tumor behaviors were naturally intended to develop HCC recurrence not only after initial LR but also after sLDLT. Patients with recurrent diseases perhaps had a higher risk or tendency to develop HCC recurrence again after LDLT. However, a theoretical explanation cannot be obtained based on the information provided in this study. Therefore, a more comprehensive study on tumor biology should be performed to clarify this issue in the future.

Generally, tumor size and number assessed by radiologic imaging examinations are currently used as selection criteria for LT. In our transplantation center, patients with unresectable HCC and willing to receive transplantation were evaluated for LT eligibility, and the policy has no difference between DDLT and LDLT. Patients with radiologic imaging of $\mathrm{HCC}$ beyond transplantation criteria would be referred to locoregional therapy for down-staging first, whereas LT would be recommended for patients with HCC meeting criteria. Nonetheless, LDLT is performed only if living donor is available, otherwise patients would be listed for waiting deceased donor for DDLT.

Additionally, interpret the radiological image of a cirrhotic liver is difficult leading to the possibility of misstaging HCC features by radiological imaging scan. Although radiologic UCSF criteria were used for assessing transplantation criteria, pathological HCC features in terms of size and number were possibility not correlate to radiologic imaging interpretation in certain ratio of patients. However, the prognostic factor was analyzed using the pathologic features of $\mathrm{HCC}$, and thus approximately $28 \%$ of patients were beyond UCSF criteria in this study. Moreover, patients who were initially beyond USCF and transplanted after down-staged by locoregional therapy could be more complicated for assessing HCC features before LT.

However, the expected surgical difficulty in sLDLT due to peritoneal adhesions caused by previous LR might be a major concern. Additionally, patients may have severe cirrhosis associated with vigorous portal collaterals, in which complete mobilization of liver for LT might be complicated. Few reports had shown that the salvage LT procedure had a longer operative time, more intra-operative blood loss, and blood transfusion. ${ }^{22}$ However, some studies have also shown that salvage LT does not increase the difficulty of transplantation. ${ }^{23,24}$ Similarly, the results showed that no significant differences in the period of complete liver mobilization and total operative time were observed between salvage and pLDLT in this study. Recipients in the sLDLT group had even less intra-operative blood loss as compared with the other group, indicating that previous LR could not definitively lead to surgical difficulty in salvage LT. Several other factors might also affect transplantation difficulty.

Numerous studies had observed a relatively higher incidence of HCC recurrence after salvage LT as compared with primary LT, but no statistical significance was observed from those reports. ${ }^{4,25,26}$ Most of these studies analyzed DDLT with a relatively small number of patients undergoing salvage LT. However, the incidence of HCC recurrence and RFS curves were significantly different between the two groups in this study as characterized by LDLT in patients with HCC. Moreover, the tumor size at the primary LR was also an important risk factor affecting HCC recurrence after sLDLT. Therefore, HCC recurrence after LT might be still strongly associated with the original tumor characteristics and behavior that should caution for HCC recurrence after sLDLT.

Moreover, despite a higher incidence of HCC recurrence, LR followed by LDLT for late-stage cirrhosis and/ or recurrent $\mathrm{HCC}$ undoubtedly remains a promising strategy that could generally prolong the life expectancy of patients with HCC. ${ }^{4,25,27,28}$ The current situation of donor shortage remains a major concern for LT, and a rational strategy to cope with long waiting lists is primary LR and salvage LT for posthepatectomy HCC recurrence. 
Nonetheless, donor safety should be the top priority for LDLT despite a dedicated gift from living donor. Currently, several unmet needs are still unsolved for improving long-term outcomes of LT regarding graft and patient survival as well. Hence, LDLT should be thoroughly considered upon the balance between donor safety, operative risk, and benefit. As such, LR should be first considered whenever $\mathrm{HCC}$ is eligible for resection, and LT could be preserved for those patients with unresectable HCC. In line with the previous intention-to-treat analyses, LR followed by sLDLT remains a promising strategy that could generally prolong the life expectancy of patients with HCC considering the period of awaiting LT, the possibility of $\mathrm{HCC}$ progression in waiting, the incidence of HCC recurrence after primary LR, and transplantable posthepatectomy recurrent HCC..$^{5,6,25,29}$ Importantly, the study also confirmed that salvage LT is a hopeful strategy offering patients with potentially curable HCC and prolong life expectancy. The OS measured from the time of HCC diagnosis could reach $52.9 \%$ at the 10th year followup for those who underwent sLDLT.

\section{Conclusion}

In summary, the inherent limitations regarding the natural entity of this retrospective study design are unavoidable. The study might also be questioned with era bias because of improvements in patient management, surgical skills, anesthesia techniques, and critical care during a long period of time from this study. However, additional subgroup analysis in terms of era evolution did not show any significant difference in our transplantation center. Moreover, given a considerable number of patients with statistical significance, the results presented here might be a remarkable evidence providing a logical strategy in these patients whenever possible. Therefore, LDLT should be considered as a promising strategy for the treatment of patients with HCC who are potential LT candidates awaiting transplantation in terms of both primary and salvage purposes to improve the overall outcomes.

\section{Acknowledgment}

The authors thank colleagues for helping with this research.

\section{Author contributions}

All authors contributed to data analysis, drafting or revising the article, gave final approval of the version to be published, and agree to be accountable for all aspects of the work.

\section{Disclosure}

All authors have no financial relationships or other potential conflicts to disclose in this work.

\section{References}

1. Dhir M, Melin AA, Douaiher J, et al. A review and update of treatment options and controversies in the management of hepatocellular carcinoma. Ann Surg. 2016;263:1112-1125.

2. Mazzaferro V, Regalia E, Doci R, et al. Liver transplantation for the treatment of small hepatocellular carcinomas in patients with cirrhosis. N Engl J Med. 1996;334:693-699. doi:10.1056/NEJM199603143341104

3. Yao FY, Ferrell L, Bass NM, et al. Liver transplantation for hepatocellular carcinoma: expansion of the tumor size limits does not adversely impact survival. Hepatology. 2001;33:1394-1403. doi:10. 1053/jhep.2001.24563

4. Bhangui P, Allard MA, Vibert E, et al. Salvage versus primary liver transplantation for early hepatocellular carcinoma: do both strategies yield similar outcomes? Ann Surg. 2016;264:155-163. doi:10.1097/ SLA.0000000000001442

5. Fuks D, Dokmak S, Paradis V, Diouf M, Durand F, Belghiti J. Benefit of initial resection of hepatocellular carcinoma followed by transplantation in case of recurrence: an intention-to-treat analysis. Hepatology. 2012;55:132-140. doi:10.1002/hep.24680

6. Majno PE, Sarasin FP, Mentha G, Hadengue A. Primary liver resection and salvage transplantation or primary liver transplantation in patients with single, small hepatocellular carcinoma and preserved liver function: an outcome-oriented decision analysis. Hepatology. 2000;31:899-906. doi:10.1053/he.2000.5763

7. Lee $\mathrm{CF}$, Cheng $\mathrm{CH}$, Wang $\mathrm{YC}$, et al. Adult living donor liver transplantation across ABO-incompatibility. Medicine (Baltimore). 2015;94:e1796. doi:10.1097/MD.0000000000000874

8. Chan KM, Yu MC, Chou HS, Wu T-J, Lee C-F, Lee W-C. Significance of tumor necrosis for outcome of patients with hepatocellular carcinoma receiving locoregional therapy prior to liver transplantation. Ann Surg Oncol. 2011;18:2638-2646. doi:10.1245/ s10434-011-1779-z

9. Wu TJ, Chan KM, Chou HS, et al. Liver transplantation in patients with hepatitis B virus-related hepatocellular carcinoma: the influence of viral characteristics on clinical outcome. Ann Surg Oncol. 2013;20:3582-3590. doi:10.1245/s10434-013-3023-5

10. Trotter JF. Liver transplantation around the world. Curr Opin Organ Transplant. 2017;22:123-127. doi:10.1097/MOT.0000000000000392

11. Chen CL, Kabiling CS, Concejero AM. Why does living donor liver transplantation flourish in Asia? Nat Rev Gastroenterol Hepatol. 2013;10:746-751. doi:10.1038/nrgastro.2013.194

12. Shukla A, Vadeyar H, Rela M, Shah S. Liver transplantation: east versus west. J Clin Exp Hepatol. 2013;3:243-253. doi:10.1016/j. jceh.2013.08.004

13. Goldaracena N, Gorgen A, Doyle A, et al. Live donor liver transplantation for patients with hepatocellular carcinoma offers increased survival vs. deceased donation. J Hepatol. 2019;70:666-673. doi:10.1016/j.jhep.2018.12.029

14. Bhangui P, Vibert E, Majno P, et al. Intention-to-treat analysis of liver transplantation for hepatocellular carcinoma: living versus deceased donor transplantation. Hepatology. 2011;53:1570-1579. doi:10.1002/ hep. 24231

15. Wong TCL, Ng KKC, Fung JYY, et al. Long-term survival outcome between living donor and deceased donor liver transplant for hepatocellular carcinoma: intention-to-treat and propensity score matching analyses. Ann Surg Oncol. 2019;26:1454-1462. 
16. Lee S, Ahn C, Ha T, et al. Liver transplantation for hepatocellular carcinoma: Korean experience. J Hepatobiliary Pancreat Sci. 2010;17:539-547. doi:10.1007/s00534-009-0167-6

17. Sugawara Y, Tamura S, Makuuchi M. Living donor liver transplantation for hepatocellular carcinoma: Tokyo University series. Dig Dis. 2007;25:310-312. doi:10.1159/000106910

18. Takada Y, Uemoto S. Liver transplantation for hepatocellular carcinoma: the Kyoto experience. $J$ Hepatobiliary Pancreat Sci. 2010;17:527-532. doi:10.1007/s00534-009-0162-y

19. Zheng SS, Xu X, Wu J, et al. Liver transplantation for hepatocellular carcinoma: Hangzhou experiences. Transplantation. 2008;85:17261732. doi:10.1097/TP.0b013e31816b67e4

20. Rhu J, Kim JM, Choi GS, et al. The impact of extra-anatomical hepatic artery reconstruction during living donor liver transplantation on biliary complications and graft and patient survival. Transplantation.2019; 1. doi:10.1097/TP.0000000000002601

21. Choi HJ, Kim DG, Na GH, et al. The clinical outcomes of patients with portal vein tumor thrombi after living donor liver transplantation. Liver Transpl. 2017;23:1023-1031. doi:10.1002/lt.24782

22. Wu L, Hu A, Tam N, et al. Salvage liver transplantation for patients with recurrent hepatocellular carcinoma after curative resection. PLoS One. 2012;7:e41820. doi:10.1371/journal.pone.0041820

23. Cucchetti A, Vitale A, Del Gaudio M, et al. Harm and benefits of primary liver resection and salvage transplantation for hepatocellular carcinoma. Am J Transplant. 2010;10:619-627. doi:10.1111/j.16006143.2009.02984.x
24. Eguchi S, Hidaka M, Tomonaga T, et al. Actual therapeutic efficacy of pre-transplant treatment on hepatocellular carcinoma and its impact on survival after salvage living donor liver transplantation. $J$ Gastroenterol. 2009;44:624-629. doi:10.1007/s00535-009-0043-9

25. de Haas RJ, Lim C, Bhangui P, et al. Curative salvage liver transplantation in patients with cirrhosis and hepatocellular carcinoma: an intention-to-treat analysis. Hepatology. 2018;67:204-215. doi:10.10 02/hep. 29468

26. Lim C, Shinkawa H, Hasegawa K, et al. Salvage liver transplantation or repeat hepatectomy for recurrent hepatocellular carcinoma: an intent-totreat analysis. Liver Transpl. 2017;23:1553-1563. doi:10.1002/lt.24952

27. Guerrini GP, Gerunda GE, Montalti R, et al. Results of salvage liver transplantation. Liver Int. 2014;34:e96-e104. doi:10.1111/liv.12497

28. Del Gaudio M, Ercolani G, Ravaioli M, et al. Liver transplantation for recurrent hepatocellular carcinoma on cirrhosis after liver resection: University of Bologna experience. Am J Transplant. 2008;8:1177-1185. doi:10.1111/j.1600-6143.2008.02229.x

29. Sarasin FP, Majno PE, Llovet JM, Bruix J, Mentha G, Hadengue A. Living donor liver transplantation for early hepatocellular carcinoma: a life-expectancy and cost-effectiveness perspective. Hepatology. 2001;33:1073-1079. doi:10.1053/jhep.2001.23311

\section{Publish your work in this journal}

Cancer Management and Research is an international, peer-reviewed open access journal focusing on cancer research and the optimal use of preventative and integrated treatment interventions to achieve improved outcomes, enhanced survival and quality of life for the cancer patient
The manuscript management system is completely online and includes a very quick and fair peer-review system, which is all easy to use. Visit http://www.dovepress.com/testimonials.php to read real quotes from published authors. 